
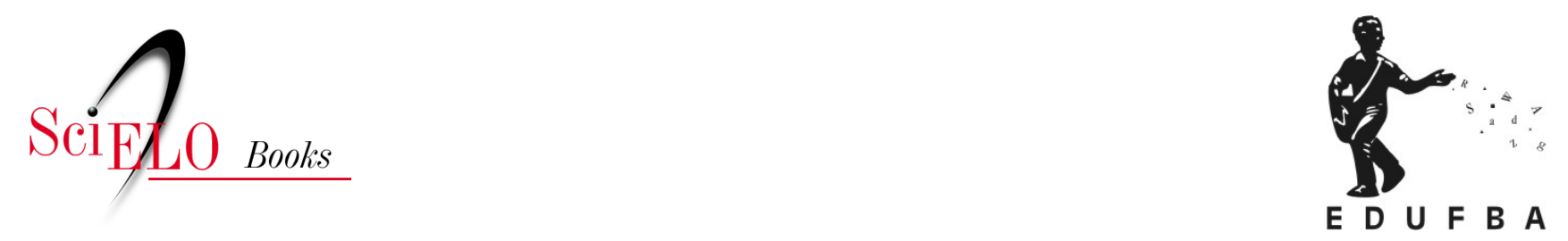

\title{
Policy \\ A insuficiência da política pública para inclusão do técnico em saúde bucal na atenção primária no Brasil
}

\author{
Dulce Maria de Lucena Aguiar \\ Paulo Frazão
}

\section{SciELO Books / SciELO Livros / SciELO Libros}

AGUIAR, D.M.L., and FRAZÃO, P. A insuficiência da política pública para inclusão do técnico em saúde bucal na atenção primária no Brasil. In: CHAVES, S.C.L. Política de saúde bucal no Brasil: teoria e prática [online]. Salvador: EDUFBA, 2016, pp. 297-318. ISBN 978-85-232-2029-7.

https://doi.org/10.7476/9788523220297.0012.

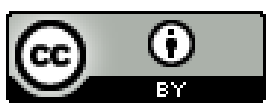

All the contents of this work, except where otherwise noted, is licensed under a Creative Commons Attribution 4.0 International license.

Todo o conteúdo deste trabalho, exceto quando houver ressalva, é publicado sob a licença Creative Commons Atribição 4.0. 


\section{A insuficiência da política pública para inclusão do técnico em saúde bucal na atenção primária no Brasil}

Dulce Maria de Lucena Aguiar

Paulo Frazão

\section{Apresentação}

O conhecimento científico de que um Cirurgião-Dentista (CD) pode dar assistência a uma porcentagem maior de usuários dos serviços odontológicos, conforme o número e o preparo do pessoal de nível técnico que compõe a sua equipe, quando comparado a um CD que trabalha sozinho, foi produzido desde a primeira metade do século XX. No que pese a ampla documentação, abrangendo vários países, sobre a relevância da participação do pessoal auxiliar na equipe de saúde bucal, tanto do ponto de vista da cobertura quanto da qualidade dos serviços e da redução dos custos, muitos programas odontológicos em serviços de atenção primária à saúde permanecem centrados na figura do CD. Uma importante iniciativa de política de saúde bucal no Brasil foi a aprovação de dispositivos normativos visando incentivar a incorporação do Técnico em Saúde Bucal (TSB) na Estratégia de Saúde da Família (ESF). Neste capítulo, sumarizamos a literatura brasileira sobre o tema e descrevemos os dispositivos normativos da política. Frente aos modestos efeitos alcançados, argumentamos pela sua reformulação. 


\section{Contextualizando o debate}

A publicação do Relatório mundial da saúde de 2006 reafirmou a importância da força de trabalho para que os sistemas de saúde produzam uma resposta mais efetiva diante dos graves e persistentes problemas que afetam a saúde das populações. São amplas as evidências de que o número e a qualidade dos trabalhadores estão positivamente associados à cobertura vacinal, extensão de cuidados primários e sobrevivência perinatal, infantil e materna. A aplicação efetiva dos recursos de cada sistema de saúde depende dos trabalhadores e de processos de gestão que assegurem melhorias quantitativas e qualitativas nas dimensões institucional, organizacional e funcional. Melhor desempenho da força de trabalho pode ser alcançado através da aplicação de duas regras cardinais para o aumento da efetividade das intervenções: simplificação e delegação. Uma abordagem em equipe é necessária não somente na gestão de indivíduos com doenças crônicas, mas no tratamento mais geral desses desafios de saúde pública. Usualmente, a prestação de cuidados em casos de doenças crônicas é mais bem realizada em esforço colaborativo. Os gargalos que impedem o alcance de objetivos de saúde nacionais e globais não serão superados sem o desenvolvimento de trabalhadores de saúde capazes, motivados e apoiados. (ORGANIZAÇÃO MUNDIAL DA SAÚDE, 2007)

Essas considerações se aplicam aos trabalhadores dos serviços odontológicos mantidos pelos sistemas de saúde. Desde as primeiras experiências envolvendo a higienista dental nos Estados Unidos, em 1913 (DUNNING, 1958), e a enfermeira dentária escolar na Nova Zelândia, na década de 1920 (FULTON, 1951), surgiu ampla documentação, abrangendo vários países, sobre a relevância da participação desse tipo de pessoal auxiliar na equipe de saúde bucal, potencializando a atuação dessa equipe, tanto do ponto de vista da cobertura quanto do ponto de vista da qualidade dos serviços e da redução dos custos. (FRAZÃO; GONZÁLES; ROSA, 1995; JOHNSON, 1992) A relevância a esse tipo de profissional está associada ao fato de poder executar a prestação direta de serviços aos usuários dos sistemas de saúde, liberando o CD para atividades mais complexas, evitando a fragmentação do trabalho e aumentando o grau de autonomia do TSB, o que possivelmente resultaria em maior impacto epidemiológico na redução da cárie e da doença periodontal. (CARVALHO, 1999)

Um estudo longitudinal de âmbito internacional examinou as tendências e mudanças na participação de higienistas dentais por meio de cinco inquéritos realizados entre 1987 e 2006, nos quais o número de países com informação so- 
bre o tema aumentou de 13 para 25. Ao longo do período de 19 anos, observou-se um aumento significativo da formação, acompanhado pela crescente melhoria nas razões higienista/população e higienista/CD em vários países, mantendo-se notavelmente consistente, mundialmente, o seu âmbito de prática clínica. Japão e Estados Unidos são os países com maior número de higienistas dentais (aproximadamente $200 \mathrm{mil}$ cada), seguidos pela Coreia do Sul (30.782 mil) e Canadá (18.350 mil). Em geral, notou-se aumento no interesse pela participação do higienista dental nas atividades de prestação direta de serviços clínicos e uma maior diversificação em termos de tipos de serviços e locais de prática. No que pesem algumas mudanças observadas, a evolução vem resultando em uma homogeneidade contínua na profissão no mundo todo. As tendências descritas têm implicações para a acessibilidade e a eficiência técnica dos serviços odontológicos e devem continuar a ser monitoradas. (JOHNSON, 2009)

A formação do técnico em saúde bucal varia de um país para outro, mas geralmente consta de um curso de dois anos realizado após a conclusão do ensino médio, diferindo em alguns países, onde a formação de higienistas pode avançar para funções expandidas e alcançar um período de três anos letivos.

Historicamente, higienistas dentais têm sido empregados como cuidadores de crianças em instituições governamentais, usualmente em programas executados nas escolas, mas, diante de mudanças demográficas e epidemiológicas, em vários países, sua participação tem sido direcionada também para adultos e idosos. (HOPCRAFT et al., 2011)

Existem evidências de que higienistas dentais prestam serviços seguros, de qualidade e eficazes, sendo geralmente bem aceitos pelo público que atendem. (GALLOWAY et al., 2004)

No Brasil, a participação do pessoal auxiliar na prestação direta de serviços teve início nos anos 1950 em atividades odontológicas realizadas em escolas e unidades básicas de saúde do Serviço Especial de Saúde Pública (SESP), mais tarde denominada de Fundação Nacional de Saúde. A limpeza dos dentes, a aplicação tópica de fluoretos e a educação em saúde eram atribuições dos auxiliares àquela época. (FRAZÃO; NARVAI, 2012)

Os altos índices de cárie dentária e de doença periodontal, os movimentos por direitos sociais, entre eles o direito à saúde, o desequilíbrio entre a demanda e a oferta de serviços de assistência odontológica e o desenvolvimento científico-tecnológico contribuíram para a expansão do emprego de pessoal auxi- 
liar nos serviços públicos odontológicos nas décadas de 1970 e 1980. Conforme Frazão, Gonzáles e Rosa (1995, p. 22),

[...] a participação deixa de localizar-se apenas em algumas instituições, como por exemplo, SESP e Instituto Nacional da Assistência Médica da Previdência Social (INAMPS), para expandir-se em direção a outras organizações públicas dos setores de saúde e de educação do país.

O argumento principal compartilhado por vários analistas em seminários e publicações é que, para melhorar os níveis de saúde bucal, dois objetivos estratégicos devem ser perseguidos: aumentar as medidas de prevenção de doenças e de promoção da saúde e capacitar auxiliares e técnicos em saúde bucal nos serviços odontológicos. Dado que os recursos são limitados, do ponto de vista da saúde pública, busca-se alcançar um equilíbrio entre a cobertura da população beneficiada e os tipos de serviços prestados nos programas de saúde. Como consequência, a participação de auxiliares e técnicos deve ser orientada, de forma coordenada, tanto para as atividades de promoção da saúde, cuja finalidade é diminuir a magnitude e a gravidade das doenças bucais, como para as atividades de tratamento ou assistência individual, cuja finalidade é aliviar o sofrimento e recuperar o dano provocado pelas lesões. (FRAZÃO; CASTELLANOS, 1999)

Frazão, na década de 1990, realizou uma pesquisa em 10 Sistemas Locais de Saúde (Silos) de cinco municípios do estado de São Paulo, com a finalidade de descrever algumas características do Pessoal Auxiliar em Odontologia (PAO) que trabalhava nesses Silos e analisar sua participação em programas municipais de saúde bucal. Nessa pesquisa, a expressão PAO fazia referência ao Técnico em Higiene Dental (THD) e ao Auxiliar de Consultório Dentário (ACD). Um questionário foi respondido por $75 \%$ dos ACD e THD dos municípios participantes da pesquisa.

Os resultados indicaram participação desse pessoal, tanto em atividades de promoção da saúde bucal como de assistência odontológica individual, variando a ênfase conforme a programação das ações em cada município. Com base nos resultados desse estudo, Frazão e Castellanos (1999) encontraram que as atividades mais frequentes de promoção da saúde bucal foram os bochechos com flúor, a evidenciação de placa bacteriana dental seguida de escovação supervisionada; atividades educativas eram realizadas em escolas e unidades básicas de saúde. No nível individual, as atividades realizadas foram aplicação 
tópica de flúor, aplicação de selante, eliminação de placa bacteriana e polimento coronário, além da inserção de materiais restauradores provisórios e definitivos. Em todos os casos, a participação do pessoal auxiliar de odontologia nos Silos foi considerada importante por contribuir para a transformação das práticas da odontologia no âmbito da saúde coletiva e do sistema de saúde em construção no Brasil.

Sanglard-Oliveira e colaboradores (2013) analisaram o autorrelato das funções executadas pelos TSB, no estado de Minas Gerais, por meio de entrevista telefônica, com amostra representativa de 231 trabalhadores. Observou-se que 71,6\% (IC 95\%, 64,4-77,5) realizavam polimento coronário, 63,2\% (IC 95\%, 56,169,7 ) faziam raspagem de cálculo e 14,7\% (IC 95\%, 10,3-20,4) condensavam e inseriam materiais restauradores. Em relação às ações preventivo-coletivas, 100\% (IC 95\%, 97,6-100,0) participavam de ações educativas, 99,0\% (IC 95\%, 96,1-99,8) demonstravam técnicas de higiene bucal, 96,6\% (IC 95\%, 92,7-98,4) realizavam a aplicação tópica de flúor, 77,9\% (IC 95\%, 71,5-83,3) realizavam visitas domiciliares e 96,6\% (IC 95\%, 92,7-98,4) realizavam ações coletivas, principalmente em escolas.

Além de se constituir no estudo mais abrangente realizado no país, correspondendo a uma amostra representativa do estado de Minas Gerais - unidade federada que ocupa a primeira posição em número de Equipes de Saúde Bucal (ESB) da ESF com a participação do TSB -, cabe destacar que mais da metade deles realizavam ações diretas na assistência odontológica individual, um aspecto nunca antes documentado no país em um estudo de similar extensão.

Os primeiros instrumentos normativos relacionados ao PAO no Brasil, mais especificamente, ao TSB, surgiram na segunda metade do século XX em contextos específicos.

A partir da década de 1970, a população brasileira passou a pressionar pelo acesso aos serviços públicos odontológicos, levando o Estado brasileiro a ampliar a oferta desses serviços. Esse fato, somado ao grande contingente de pessoal auxiliar que vinha exercendo suas funções em clínicas privadas, favoreceu a aprovação do Parecer n. ${ }^{\circ} 460 / 75$ do Conselho Federal de Educação (CFE), o qual autorizava e estabelecia exigências para a formação do ACD e do THD. Compõe esse documento um conjunto de diretrizes com a finalidade de criar, disciplinar e regular o funcionamento de cursos para formação desse tipo de pessoal auxiliar no país. 
O THD, a partir de 1979, passa a ter destaque nacional, tornando-se alvo de intensa polêmica. A partir daí, em seus quase 30 anos de existência jurídica infralegal, as funções atribuídas a esse profissional foram alvo de diversos debates. Em seu apoio, manifestaram-se os sanitaristas reformistas, inicialmente pautados por princípios administrativos, como por exemplo, a eficiência produtiva, e alguns anos depois, impulsionados pelas ideias de Alma-Ata (saúde como direito de todos) e a reforma dos sistemas de saúde. (FRAZÃO; NARVAI, 2009) Contestando a presença desses trabalhadores nos serviços odontológicos, estavam lideranças profissionais da categoria odontológica, pautadas pelo princípio de defesa das competências consideradas exclusivas dos cirurgiões-dentistas sob a égide do modelo liberal-privatista. (AGUIAR et al., 2014)

Passados nove anos, o Conselho Federal de Odontologia (CFO), pressionado por ações e movimentos de defesa desses trabalhadores, disciplinou, através da Decisão 26/84, o exercício daquelas ocupações, reconhecendo-as como atividades no âmbito da profissão odontológica. (AGUIAR, 2010)

Com o passar dos anos, o CFO, com vistas à defesa de seus interesses, realizou modificações naquela Decisão. Com base nas recomendações contidas no relatório da I Conferência Nacional de Saúde Bucal, realizada em 1986, constituiu uma comissão especial para ponderar sobre alguns tópicos como o exercício das funções de ACD e THD sem habilitação legal e a ausência de regulamentação dessas ocupações pelo Ministério do Trabalho, com alteração dos capítulos IV e V da Decisão 26/84, aprovada pela Resolução 155/84, aliada à deliberação 157/87, que ampliava as funções do ACD com relação à prevenção e controle da carie dentária e à manutenção do equipamento odontológico.

As Resoluções 153, 185 e 195, aprovadas em 1993, visavam também adequar as atribuições do ACD e THD aos interesses do CFO. A Resolução 185 alterou o item "n" do capítulo IV, cuja redação era "polir restaurações", para "polir restaurações, vedando-se a escultura". A Resolução 14/2000 acrescentou à disposição relacionada ao ACD, atribuições referentes à "lavagem, desinfecção e esterilização do instrumental e do consultório”, referentes à biossegurança e que não estavam explicitadas na Resolução. 185/93 (CARVALHO, 1999)

Para a inscrição do THD nos conselhos regionais, a apresentação do diploma é exigida desde 1988. Antes disso, bastava uma carta de um CD comprovando a experiência de um ano desse profissional na função. Através da Decisão 47/2003 do CFO, a denominação "Atendente de Consultório Dentário" foi alterada para "Auxiliar de Consultório Dentário". A partir de junho de 2000, o 
CFO passou também a exigir, para inscrição do ACD nos conselhos regionais de odontologia, a apresentação de um certificado ou diploma conferido por curso de qualificação autorizado pelo Conselho Estadual de Educação. Com vistas à regulamentação das profissões de ACD e THD, em 1989 foi apresentado à Câmara dos Deputados o Projeto de Lei (PL) n. ${ }^{\circ}$ 2244/89 (BRASIL, 1989), de autoria do deputado Robson Marinho (PSDB/SP), no qual o próprio autor fez um substitutivo ao substitutivo, tendo sido reapresentado em 1991 (PL n. ${ }^{\circ}$ 284/91), pelo deputado Augusto Carvalho filiado ao Partido Comunista Brasileiro, pelo Distrito Federal (BRASIL, 1991). O PL n. ${ }^{\circ} 284 / 91$ foi aprovado pelas comissões da Câmara e encaminhado ao Senado Federal em 19/04/1993. Em nova legislatura, o Projeto de Lei da Câmara (PLC) recebeu o n. ${ }^{\circ}$ 53/93 (antigo 284/91), tramitou no Senado Federal e foi aprovado em 8/12/1993. Entretanto, após tramitar durante cerca de cinco anos no Congresso Nacional, o ex-presidente Itamar Franco vetou o PLC n. ${ }^{\circ} 53$ no penúltimo dia de 1993, sob os argumentos de que a regulamentação restringia o mercado de trabalho, delimitava o campo de ação, desmotivava o aperfeiçoamento profissional impedindo a plena liberdade contratual, para atender interesses específicos ainda desconhecidos, mas que poderiam estar ligados à influência do CFO, pois, como foi mencionado, o órgão disciplinador do exercício profissional pautou o assunto em diferentes ocasiões naquele ano.

Em 22/02/2000, o PL n. ${ }^{\circ} 2.487$ foi apresentado pelo deputado Agnelo Queiroz (PCdoB/DF) (BRASIL 2000). O PL tramitou na Comissão de Trabalho, de Administração e Serviço Público (CTASP), mas foi rejeitado pelo relator do projeto, o Deputado Freire Junior (PMDB/TO) sob os argumentos de que a proposta de regulamentação profissional não atendia as determinações da CTASP, segundo as quais, a atividade deveria exigir conhecimentos teóricos e científicos avançados; ser exercida por profissionais de curso superior; e se não regulamentada, poderia trazer riscos de dano social no tocante à saúde, ao bem-estar e à segurança da coletividade, além de outros aspectos que ensejaram o veto ao PLC 53/93 (BRASIL 2000). O PL n. ${ }^{\circ} 1140 / 2003$, de autoria do deputado Rubens Otoni (PT/GO), teve por finalidade regulamentar o exercício das profissões de THD e ACD, prevendo suas atribuições e direitos, seus deveres e vedações. (BRASIL 2003) Para justificá-lo, seu autor esclarece:

[...] o presente projeto de lei foi originalmente apresentado em 1989 pelo Deputado Robson Marinho (PL n. ${ }^{\circ}$ 2.244/89), tendo sido reapresentado pelo Deputado Augusto carvalho em 1991 (PL n. ${ }^{\circ}$ 284/91) e pelo Deputado 
Agnelo Queiroz em 2000 (PL n. ${ }^{\circ}$ 2.487/oo), em face do arquivamento da proposição, conforme o Regimento Interno desta Casa.

O referido projeto teve dois substitutivos, sendo um da Comissão de Seguridade Social e Família e outro da Comissão de Trabalho, Planejamento e Serviço Público, tendo sido aprovado pela Comissão de Constituição e Justiça e de Cidadania da Câmara dos Deputados em 2006 e encaminhado ao Senado Federal para análise em 27/12/2006. De acordo com o referido PL e seus substitutivos, as profissões de THD e ACD passariam a ser denominadas respectivamente, de TSB e Auxiliar de Saúde Bucal (ASB), podendo ser exercidas apenas por aqueles que possuíssem diploma ou certificado que atendessem às normas do CFE. A matéria também determinava que os TSB e ASB devessem ser registrados no CFO e no Conselho Regional de Odontologia e que seu trabalho deveria ser sempre supervisionado por um CD. Em 9/1/2007, o projeto foi apresentado ao Senado Federal (PLC 3/2007), tramitou pela Comissão de Assuntos Sociais e pela Comissão de Constituição, Justiça e Cidadania (BRASIL 2007) e foi aprovado em 4 de dezembro de 2008, dando origem à Lei 11.889 que regulamenta o exercício das profissões de de Técnico em Saúde Bucal e Auxiliar em Saúde Bucal (BRASIL 2008). Torna-se importante mencionar sob que cenários foram travadas tais lutas para que as referidas profissões fossem regulamentadas. Esse cenário não era neutro e por vezes mostrava-se desfavorável e profundamente adverso às mudanças desejadas. Nem sempre as autoridades representativas da categoria odontológica mantiveram-se a favor do pleito.

Narvai e colaboradores (1990) discutiram sobre a formação e incorporação do THD aos serviços de saúde, incluindo a aceitação desse profissional pelos dirigentes da categoria, compondo assim ESB, tanto no setor público quanto no privado. Os autores apontaram os seguintes motivos que levavam os dirigentes, na época, a rejeitarem o trabalho do THD: reserva de mercado; a incapacidade do THD de realizar trabalhos de qualidade comparada à do CD; e o risco que o $\mathrm{CD}$ assumiria ao trabalhar com o THD, pois, perante a justiça, o CD é o responsável pelo trabalho executado por aquele auxiliar.

Em uma publicação editada pela secretaria da Rede de Escolas Técnicas do Sistema Único de Saúde (RET-SUS), um membro da Associação Brasileira de Cirurgiões-Dentistas e da Federação Nacional dos Odontologistas posicionou-se contra a atuação do THD realizando raspagem gengival e inserção e con- 
densação de material restaurador, atividades para ele consideradas exclusivas de um CD.

Narvai e Frazão (1999) argumentaram que grande parte das críticas referentes às competências do THD e do ACD deve-se ao desconhecimento de dispositivos legais já existentes e considerados suficientes para disciplinar o trabalho das ESB sob a coordenação de um CD. Para esses autores, além do desconhecimento acerca dos dispositivos legais já existentes, a principal polêmica diz respeito à reserva de mercado por parte do CD.

Apesar de uma longa espera (mais de 20 anos), a Lei n. ${ }^{\circ} 11.889$, de 24 de dezembro de 2008, regulamentou o exercício das profissões de TSB e de ASB. Em seu artigo $5^{\circ}$, constam as competências do TSB, as quais devem ser realizadas sempre sob a supervisão do CD. No artigo $9^{\circ}$ da Lei, constam as atividades de competência do ASB, as quais deverão ser exercidas sob a supervisão do CD ou do TSB. Após a regulamentação, foram determinadas as seguintes atividades exclusivas para o TSB:

[...] participar de treinamento e capacitação de ASB e de agentes multiplicadores das ações de promoção à saúde; participar de ações educativas por meio de ações de promoção da saúde e da prevenção de doenças bucais; participar de levantamentos e estudos epidemiológicos, exceto na função de examinador; ensinar técnicas de higiene bucal e realizar prevenção de doenças bucais por meio da aplicação tópica de flúor, seguindo orientação do CD; fazer a remoção do biofilme, conforme indicação técnica definida pelo CD; supervisionar o trabalho do ASB quando delegado pelo $\mathrm{CD}$; realizar fotografias e tomadas de uso odontológico exclusivamente em consultórios ou clínicas odontológicas; inserir e distribuir no preparo cavitário materiais odontológicos na restauração dentária direta, vedado o uso de materiais e instrumentos não indicados pelo CD; proceder à limpeza e antissepsia do campo operatório, antes e após atos cirúrgicos, inclusive em ambientes hospitalares; remover suturas; aplicar medidas de biossegurança no armazenamento, manuseio e descarte de produtos e resíduos odontológicos; realizar isolamento do campo operatório; exercer todas as competências no âmbito hospitalar, bem como instrumentar O CD em ambientes clínicos e hospitalares. (BRASIL, 2008)

Embora estivesse estabelecida (normalizada) no campo da educação há mais de 30 anos, e há mais de 20 anos, em termos de exercício profissional, a regulamentação da profissão só veio a acontecer em 2008. 
O SUS exerceu papel importante no processo de regulamentação dessas profissões, na medida em que assumiu a prioridade de desenvolvimento de recursos humanos para a profissionalização do trabalhador da rede de atenção básica, com vistas a reorientar e qualificar a prática profissional.

Frazão e Narvai (2011) analisaram as competências do TSB, constantes na Lei n. ${ }^{\circ} 11.889 / 08$. Foram comparadas as competências definidas no referido instrumento legal com aquelas previstas no Parecer n. ${ }^{\circ} 460 / 75$ do CFE e na Resolução n. ${ }^{\circ}$ 63/2005 do CFO. Os autores concluíram que as competências aprovadas na Lei foram distribuídas em número menor de itens, em comparação aos dois outros documentos, do ponto de vista qualitativo, mas os resultados da análise permitiram retratar avanços obtidos com a regulamentação da profissão, nos termos aprovados, em todas as áreas de competência. Houve impacto positivo para o processo de trabalho em saúde, tanto com relação à cooperação interprofissional quanto à supervisão técnica das atividades, resultando em uma conquista relevante dos trabalhadores da área e também numa contribuição significativa para avançar na ampliação do acesso da população aos serviços odontológicos.

Em âmbito mundial e também no Brasil, a assistência odontológica é ofertada predominantemente no mercado de prestação de serviços de saúde sob os princípios do modelo liberal-privatista. (CHAVES, 2012; NARVAI; FRAZÃO, 2008)

No Brasil, a partir de 2000 , foi aprovado incentivo financeiro para impulsionar a inclusão das ESB na ESF. (BRASIL, 2000) A Política Nacional de Saúde Bucal, discutida no âmbito da $3^{\text {a }}$ Conferência Nacional de Saúde Bucal e aprovada na comissão de gestores das três esferas de governo do SUS, contribuiu para a ampliação da força de trabalho odontológica nos serviços públicos, propiciando uma nova perspectiva rumo à consolidação legal da profissionalização do TSB. (BRASIL, 2004) Os principais objetivos da implantação das ESB na ESF foram: melhorar as condições de saúde bucal da população, reorientar as práticas de atenção na área, observando os padrões de qualidade e o impacto das ações realizadas e ampliar o acesso da população às ações de promoção, prevenção e recuperação da saúde bucal, com consequente melhoria de seus indicadores.

Admite-se que para os profissionais da área, em especial para o dentista, a atuação na ESF traz alguns desafios, como por exemplo, abandonar o isolamento a que estava habituado, compartilhando com outro profissional a prá- 
tica antes restrita ao consultório odontológico; passar a trabalhar em equipe multiprofissional, onde é necessário desenvolver competências, inclusive de natureza relacional, para além de seu núcleo de competência saber, e de seus conhecimentos específicos; compreender a determinação social do processo saúde-doença mobilizando recursos do território, planejando, articulando e avaliando as ações de proteção à saúde bucal junto às demais ações de saúde. Em 2004, foi lançada a Política Nacional de Saúde Bucal, o Brasil Sorridente, tendo dentre seus pressupostos a qualificação da atenção básica e a incorporação da ESF como importante estratégia na reorganização da atenção básica. (BRASIL, 2004)

A ESF aparentou ser, à primeira vista, uma política nacional favorável à administração e à melhor composição da força de trabalho odontológica nos serviços públicos. Sua principal variável normativa fazia a distinção de ESB - modalidade I (sem TSB), e modalidade II (com TSB) -, condicionando as transferências federais aos municípios (piso de atenção básica variável da saúde bucal).

A ESB pode ser composta por um CD e um ASB (modalidade I). Acrescendo-se um TSB, a equipe passa a ser de modalidade II. A Portaria GM n. ${ }^{\circ} 267$, de 6 de março de 2001, estabelecia uma diferença de $23 \%$ por ano para custeio entre as duas modalidades (13 mil para 16 mil reais). No início, o incentivo federal aos municípios interessados foi limitado a uma ESB para cada duas ESF. Somente com a Portaria GM n. ${ }^{0}$ 673/2003 que o financiamento foi autorizado na proporção de uma para um considerando o teto máximo de transferência correspondente ao número de equipes de saúde da família.

Com a Portaria GM n. ${ }^{\circ}$ 74/2004, a equipe com TSB passou a receber do Ministério da Saúde um equipamento odontológico completo a ser utilizado pelo TSB, para a realização de atividades planejadas e supervisionadas pelo CD, e a diferença passou a $29,4 \%$ por ano para custeio (20,4 mil para 26,4 mil reais). Assim, os incentivos para essa área cresceram, criando condições para a reorientação das ações.

A Portaria n. ${ }^{0}$ 1.599, do Ministério da Saúde (BRASIL, 2011), definiu valores de financiamento do Piso da Atenção Básica Variável para as equipes de saúde da família, ESB e aos agentes comunitários de saúde, instituídos pela Política Nacional de Atenção Básica. No artigo $2^{\circ}$, são definidos valores do incentivo financeiro das ESB nas modalidades I e II, segundo critérios estabelecidos pela Política Nacional de Atenção Básica, da seguinte forma: para as ESB na moda- 
lidade I, serão transferidos R $2.100,00$ a cada mês, por equipe; e para as ESB na modalidade II, serão transferidos $\mathrm{R} \$ 2.800,00$ a cada mês, por equipe. $\mathrm{A}$ diferença alcançou $30 \%$.

A Portaria n..$^{\circ}$ 978, de maio de 2012 , reajustou esses valores, passando o incentivo da ESB modalidade I para R $\$ 2230,00$ por equipe, a cada mês; e o da modalidade II para $\mathrm{R} \$ 2.980,00$ - elevando a diferença para 33,6\%.

\section{A situação atual do TSB na atenção primária à saúde}

No que pesem todos os esforços para impulsionar a inclusão do TSB na atenção primária à saúde sob os princípios da ESF, nenhum estudo analisou detidamente a questão no Brasil, razão pela qual se justifica examinar o efeito dessa política de incentivo a fim de apreciar a extensão das mudanças que a medida vem produzindo e eventualmente as correções de rumo necessárias.

Para isso, foram consultados dados do portal do Departamento de Atenção Básica da Secretaria de Atenção à Saúde do Ministério da Saúde, relativos ao número de ESB implantadas nas modalidades I e II admitindo-se que eles expressam, de um lado, a força indutora da política para apoiar a estruturação de uma atenção primária mais abrangente, e de outro, o grau de aderência dos entes municipais à formulação e implementação da política pública. Além disso, foram recolhidos dados do CFO, referentes a setembro de 2015. No que pesem suas limitações - os dados podem conter profissionais inativos; que não exercem atividade na assistência odontológica e pode ser expressivo o subregistro dos que exercem atividades como auxiliar de saúde bucal -, registros sobre o exercício profissional podem ser úteis para caracterizar em linhas gerais a composição corrente da força de trabalho nos serviços odontológicos do país, refletindo em certo sentido o modelo de prática odontológica predominante. A magnitude dos desequilíbrios quantitativos na razão TSB/CD e razão ASB/CD foi apurada e os valores foram comparados, admitindo-se a hipótese de que as diferenças de valores entre as razões observadas podem ser indicativas do grau de alcance da política pública, ou seja, sua efetividade para induzir a reestruturação do modelo de prática odontológica na principal estratégia de atenção primária à saúde no país.

Na Tabela 1 é apresentada a distribuição do número de ESB segundo as modalidades I e II e, na Figura 1, a distribuição percentual. Pode-se observar que, apesar dos esforços descritos, persiste um desequilíbrio considerável entre as duas modalidades de ESB. A proporção de equipes modalidade II, em 2001, 
estava em 10\%; reduziu para 7,2\%, em 2005; em 2010, estava em 8,1\%; e, em setembro de 2015 , correspondia a 9,1\%, mostrando claramente a insuficiência da política pública para impulsionar a inclusão do TSB nas equipes multiprofissionais da atenção primária na ESF.

Tabela 1 - Número de equipes de saúde bucal (ESB) nas modalidades I e II nos anos de 2001, 2005, 2010 e 2015

\begin{tabular}{c|c|c|c}
\hline Ano & ESB & Modalidade I & Modalidade II \\
\hline 2001 & 171 & 154 & 17 \\
\hline 2005 & 11.751 & 10.898 & 853 \\
\hline 2010 & 20.103 & 18.457 & 1.646 \\
\hline 2015 & 24.566 & 22.309 & 2.257 \\
\hline
\end{tabular}

Fonte: Brasil (2016).

Nota: Modalidade I: inclui CD e ASB sem TSB; modalidade II: inclui CD, ASB e TSB; mês de referência: setembro 2015 .

Figura 1 - Percentual de equipes de saúde bucal (ESB) nas modalidades I e II nos anos de 2001, 2005, 2010 e 2015

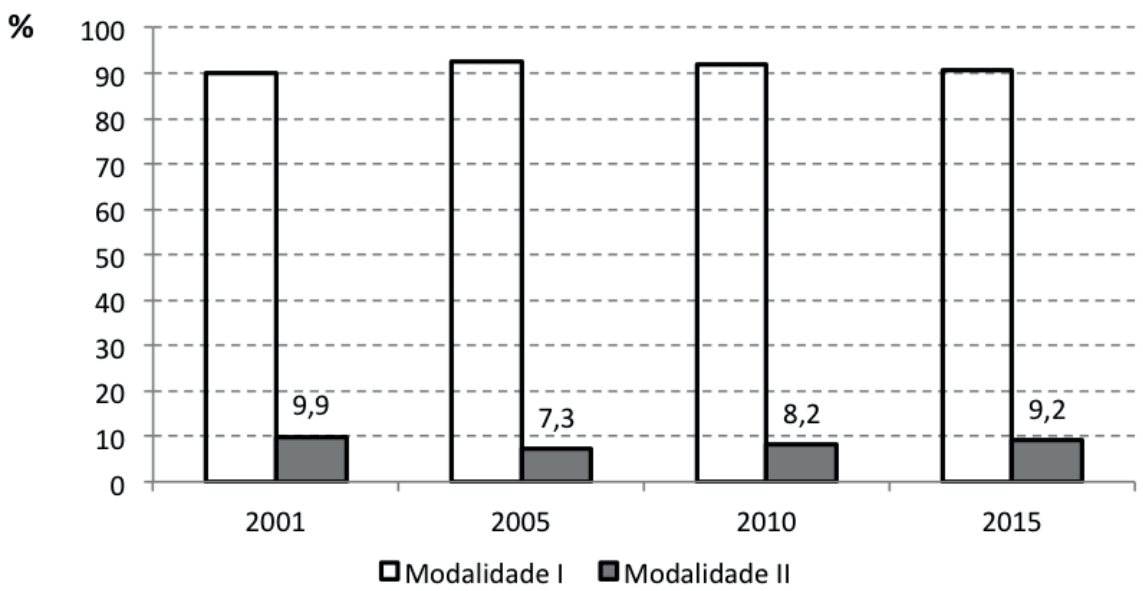

Fonte: Brasil (2016).

Nota: Modalidade I: inclui CD e ASB sem TSB; modalidade II: inclui CD, ASB e TSB; mês de referência: setembro 2015.

Em setembro de 2015, dentre as 24.566 ESB implantadas no Brasil, 2.257 eram equipes de modalidade II (9\%), sendo que 725 estavam concentradas no estado de Minas Gerais, seguido do Paraná (373) e São Paulo (243). Esses três 
estados juntos concentravam praticamente $60 \%$ do total de ESB de modalidade II implantadas no Brasil.

Prescindir da presença do TSB na ESB seria considerado aceitável somente no início do processo de implantação das ESB, tendo em vista sua importância para o aumento da cobertura e para a melhoria da qualidade da atenção à saúde bucal, criando condições mais favoráveis para a integralidade do cuidado e para a universalização do acesso da população a esse tipo de serviço de saúde.

No âmbito da prática odontológica como um todo, registros do exercício profissional indicavam uma força de trabalho composta predominantemente por CD. Na Tabela 2, é apresentada a distribuição absoluta e relativa da composição estimada da força de trabalho no Brasil. Em setembro de 2015, estavam registrados 276.711 CD, 21.539 TSB e 111.630 ASB no CFO (Tabela 2), resultando numa proporção de apenas $5 \%$ de TSB em relação ao total da força de trabalho. Isso equivalia a uma razão de sete TSB para cada 100 dentistas (Tabela 2). Mesmo se considerarmos a soma de ASB e TSB, a razão é bastante desfavorável (um para cada dois dentistas), correspondendo à mesma relação encontrada na década de 1950 em países com tradição desse tipo de profissional na força de trabalho. (DUNNING, 1958)

Tabela 2 - Força de trabalho odontológica brasileira nos serviços em geral e na ESF de
acordo com a categoria profissional

\begin{tabular}{c|c|c|c|c|c|c}
\hline $\begin{array}{c}\text { Categoria } \\
\text { profissional }\end{array}$ & $\begin{array}{c}\text { Serviços } \\
\text { odontológicos }\end{array}$ & $\%$ & $\begin{array}{c}\text { Razão } \\
\text { ASB/CD }\end{array}$ & ESF $^{2}$ & $\%$ & $\begin{array}{c}\text { Razão } \\
\text { ASB/CD }\end{array}$ \\
\hline CD & 276.711 & 68 & & 24.566 & 48 & \\
\hline TSB & 21.539 & 5 & $7 / 100$ & 2.257 & 4 & $8 / 100$ \\
\hline ASB & 111.630 & 27 & $40 / 100$ & 24.566 & 48 & $1 / 1$ \\
\hline
\end{tabular}

Fonte: CFO (2015), Brasil (2016).

Nota: Não foram incluídos técnicos de prótese dentária e auxiliares de prótese dentária.

A despeito da política pública implementada no âmbito do SUS, a relação entre o número de TSB e o número de CD correspondeu a uma razão praticamente igual no âmbito da ESF e nos serviços odontológicos em geral (7/100 para 8/100), notando-se uma diferença significativa apenas na relação entre o número de ASB e o número de CD. Mesmo que o subregistro de auxiliares ain- 
da seja expressivo nos serviços odontológicos, cabe destacar a efetividade da política para induzir a inclusão de auxiliares de saúde bucal na ESF.

Comparando a inclusão do TSB nas equipes da ESF e a composição da força de trabalho nos serviços odontológicos, os resultados sugerem que a política pública pode ter sido muito relevante para sinalizar a necessidade de inclusão do TSB na equipe, entretanto, não foi capaz de produzir uma modificação expressiva na composição da força de trabalho no âmbito da principal estratégia de atenção primária à saúde em curso no país.

Diante dos resultados observados, é lícito admitir que o quadro tende a permanecer estagnado se a política não sofrer modificações, significando baixo grau de reestruturação do modelo de prática odontológica na principal estratégia de atenção primária à saúde no país.

Por outro lado, havendo vontade para reformular a política pública de inclusão do TSB na equipe multiprofissional, um componente da política que não pode ser subestimado diz respeito aos valores financeiros transferidos aos entes municipais dispostos a implementá-la. Esse componente é ainda mais importante num contexto de subfinanciamento do subsistema público de saúde, do qual mais de $70 \%$ da população depende.

Frente aos modestos efeitos produzidos pela política, é razoável aceitar que os valores transferidos não foram suficientes para impulsionar sua inclusão na equipe multiprofissional. Mesmo considerando que, entre 2001 e 2012, a diferença percentual entre os valores transferidos para o custeio da modalidade II (com TSB) em relação à modalidade I (sem TSB) aumentou de $23 \%$ para $33,6 \%$, a resposta dos entes municipais à política não se modificou ao longo do período. Assim, é lícito admitir que, em havendo espaço para sua reformulação, é crucial discutir e pactuar com os gestores municipais e estaduais do SUS, valores que expressem uma participação mais adequada dos três níveis de gestão no financiamento da política.

Além disso, é imprescindível investigar os principais determinantes ligados a essa situação, e identificar aqueles que possam ser objeto de regulação e formulação de políticas a fim de suplantar as barreiras existentes. Para produzir os efeitos esperados, no que pese sua importância, é crucial reconhecer que a política não pode se apoiar apenas no componente financeiro. É preciso, numa futura reformulação, olhar para outras políticas e esforços que estão em curso, como por exemplo, as iniciativas envolvendo a gestão do trabalho e da educação na saúde; e as ações de melhoria do acesso e da qualidade da atenção básica. 
Nesse sentido, Aguiar e colaboradores (2014) realizaram um estudo em quatro pontos diferentes do país para produzir informações científicas sobre a participação do TSB na ESB da ESF. O propósito foi investigar como diferentes agentes sociais olhavam para a participação de técnicos em saúde bucal no desempenho de ações diretas, com o objetivo de compreender as disposições simbólicas associadas. Partiu-se do pressuposto de que a ESF em desenvolvimento no país é atravessada por diferentes interesses ideológicos e sanitários que refletem distintos projetos de sistema de saúde e modelos de atenção. De acordo com Campos (2007), existem dois grandes projetos sanitários para o país: um se refere às tradições dos sistemas nacionais de saúde e o outro à tradição liberal-privatista. Esses campos são considerados dois conceitos abstratos indicativos de projetos políticos articulados a partir de interesses e valores distintos. Segundo o autor, existe uma miríade de combinações entre eles. O modo liberal-privatista é apoiado pelos prestadores privados. Completam essa composição, partidos e políticos com tendência conservadora, além de profissionais que defendem o mercado como ordenador das relações sociais. Há nesse modelo, o estímulo econômico à produção de atos sanitários, onde a lógica da atenção à saúde é a individual, privilegiando os interesses privados, na medida em que estimula a prática prescritiva de exames e medicamentos. Por outro lado, a tradição dos modelos nacionais de saúde foi construída em articulação com a luta dos trabalhadores em prol de políticas públicas ou do socialismo, particularmente em países europeus no século passado. Nesse tipo de tradição foram propostos modos alternativos à tradição liberal para organizar o cuidado à saúde. Investiu-se na constituição de um sistema interligado de serviços, cuja organização baseia-se na integralidade da atenção, onde o planejamento e a programação devem ocorrer com base nas necessidades de saúde e nas possibilidades tecnológicas e financeiras para enfrentá-las e não na demanda de clientes por procedimentos e atos sanitários.

Essas diferentes visões se expressam na tradição liberal-privatista da profissão odontológica, e em valores que emergem a partir da aprovação da Constituição de 1988, no Brasil, que define a saúde, e por extensão a saúde bucal, como um direito humano. (NARVAI; FRAZAO, 2008)

Simultaneamente, num nível mais intermediário, Aguiar e colaboradores (2014) admitiram o pressuposto que essas diferentes visões sofrem relevantes mediações segundo os diversos focos de interesse e diferentes repertórios de habilidades e perspectivas que os agentes reconhecem no trabalho na atenção 
primária. Para transitar entre esses níveis, recorreu-se à contribuição de Pierre Bourdieu, em especial, o aporte teórico por ele utilizado para a superação da antinomia entre as interpretações internalistas e externalistas dos fenômenos sociais. De um lado, os que sustentam que, para compreender o significado das ações humanas, basta sistematizar o conteúdo das narrativas das pessoas, conectá-las aos ritos ou momentos de fruição coletiva; e de outro, outra tradição, representada por pesquisadores que procuram relacionar o conteúdo ao contexto, interpretando o significado das ações com base em estruturas mais gerais ligadas ao mundo social ou econômico. Para contrastar essas duas importantes tradições de explicação sociológica, onde se localizam o legado de várias perspectivas, cada qual com suas ferramentas de análise e características próprias, Bourdieu propôs a noção de campo simbólico como um microcosmo dotado de leis próprias que, ao mesmo tempo, que jamais escapa às determinações do macrocosmo, dispõe de uma autonomia parcial mais ou menos acentuada para mediar pressões externas mais gerais. (BOURDIEU, 1996)

Como uma cultura biomédico-centrada permanece orientando a organização do processo de trabalho das equipes, nas quais cada profissional tende a operar de forma isolada sob a lógica da produção de procedimentos (FRANCO; MERHY, 2007), para interpretação do material, foram empregados ainda conhecimentos relacionados aos determinantes de colaboração interprofissional (SAN MARTÍN-RODRÍGUEZ et al., 2005) considerados como um recorte temático útil para codificar as forças que orientam a interação profissional, seja para induzir o abandono de disposições competitivas entre os trabalhadores, seja para incentivar uma prática colaborativa.

Um pesquisador conduziu 24 entrevistas em profundidade com dentistas, TSB e gerentes de unidades de saúde. Com base no discurso dos agentes, foram identificadas disposições simbólicas associadas a determinantes interacionais, organizacionais e sistêmicos ligados à participação dos TSB nas ESB da ESF. Entre os primeiros, foram identificados aspectos interprofissionais, como, por exemplo, o sentimento de incompetência do CD para supervisionar as atividades do TSB, baixo grau de confiança e disposição para compartilhar o trabalho. Em nível organizacional, as disposições simbólicas denotaram aspectos ligados à falta de um projeto consistente de atenção primária ou à baixa capacidade para implementá-lo, dois vértices do conceito de triângulo do governo formulado por Matus (1997), ambos associados à falta de apoio e de atividades de educação permanente. Em nível sistêmico, os discursos remeteram a diferen- 
tes aspectos ligados ao sistema de profissões, à regulação do trabalho, entre outros aspectos normativos presentes nos sistemas de saúde e de educação. (AGUIAR, 2010)

Assim, ao olhar para outras políticas e esforços que estão em curso, como por exemplo, as iniciativas envolvendo a gestão do trabalho e da educação na saúde, e as ações de melhoria do acesso e da qualidade da atenção básica, descortinam-se diferentes possibilidades para formular propostas que possam dotar, de maior consistência, as iniciativas para impulsionar a inclusão do TSB na atenção primária.

Nesse aspecto, os especialistas, em encontros de administradores e técnicos do serviço público odontológico, têm recomendado que seja assegurada a presença do TSB em todas as ESB, extinguindo a distinção entre equipe modalidade I e modalidade II, de modo a que, por ESB, seja compreendido necessariamente a presença do CD, TSB e ASB. Ausência do TSB deveria ser considerada uma forma precária e transitória, devendo a gestão estadual e municipal assumir compromisso com sua implantação em um prazo pactuado. (ENATESPO, 2010) Zanetti (2012) postulou que a implantação das ESB deveria ser acompanhada de exigências de contrapartidas de estados e municípios, como, por exemplo, contrapartidas financeiras (cofinanciamento federativo), contrapartidas políticas (ações de apoio à política nacional, como a realização de cursos, treinamento, capacitação, oficinas, entre outras) e contrapartidas técnicas (necessidade de demonstração de viabilidade e eficiência estrutural e operacional dos sistemas locais de saúde bucal etc.).

Encontros de administradores e técnicos do serviço público odontológico realizados em Belo Horizonte (2012) e em Teresina (2014) também têm apontado para as limitações da política de inclusão, defendendo-se sua reformulação com a finalidade de fortalecer o processo de inclusão do TSB nas ESB da ESF, transformando as ESB tipo I para ESB tipo II; garantir "plena" competência e atribuição do TSB no exercício profissional; promover junto aos municípios a implantação de equipes modalidade II na ESF, otimizar os processos de trabalho; e afirmar o TSB como recurso estratégico para consolidação da política de saúde bucal coletiva brasileira. Tem sido ressaltada ainda a importância da atuação junto aos órgãos públicos, seja para impulsionar a criação de cargos de ASB e TSB, no Plano de Cargos, Carreiras e Salários; adequar as denominações de acordo com a Lei no ${ }^{0} 11.889 / 2008$; e também fomentar junto à gestão estadual incentivo às ESB com a participação do TSB. 
Assim, pode-se concluir que, apesar dos reajustes crescentes nos incentivos federais no âmbito da Política Nacional de Saúde Bucal, observa-se persistente desequilíbrio entre as ESB de modalidades I e II, justificando-se abertura de debate para a reformulação da política pública com a finalidade de expandir a inclusão do TSB nas ESF.

\section{Referências}

AGUIAR, D. M. L. A participação do técnico em saúde bucal na estratégia saúde da família:um olhar em municípios estruturados. 2010. 139 f. Tese (Doutorado em Serviços de Saúde Pública)-Universidade de São Paulo, São Paulo, 2010.

AGUIAR, D. M. L. et al. Oral health technicians in Brazilian primary health care: potentials and constraints. Cadernos de Saúde Pública, Rio de Janeiro, v. 30, n. 7, p.1560-1570, jul. 2014. BOURDIEU, P. Razões práticas: sobre a teoria da ação. Campinas, SP: Papirus, 1996.

BRASIL. Congresso Nacional. Câmara dos Deputados. Projeto de Lei n 2244, de 11/05/1989, que regulamenta o exercício das profissões de Técnico em Higiene Dental e de Atendente de Consultório Dentário. Disponível em: <http://www.camara.gov.br/proposicoesWeb/ fichadetramitacao?idProposicao=201383>. Acesso em: 5 nov. 2015 .

BRASIL. Congresso Nacional. Câmara dos Deputados. Projeto de Lei no 284, de 4/04/1991, que regulamenta o exercício das profissões de Técnico em Higiene Dental e de Atendente de Consultório Dentário. Disponível em: <http://www.camara.gov.br/proposicoesWeb/ fichadetramitacao?idProposicao $=201383>$. Acesso em: 8 jun. 2016

BRASIL. Congresso Nacional. Senado Federal. Projeto de Lei da Câmara nº 53, de 23/04/1993, que regulamenta o exercício das profissões de Técnico em Higiene Dental e de Atendente de Consultório Dentário. Disponível em: <http://www25.senado.leg.br/web/atividade/ materias/-/materia/20617/pdf>. Acesso em: 8 jun. 2016.

BRASIL. Congresso Nacional. Câmara dos Deputados. Projeto de Lei n 2487, de 22/02/2000, que regulamenta o exercício das profissões de Técnico em Higiene Dental e de Atendente de Consultório Dentário. Disponível em: <http://www.camara.gov.br/proposicoesWeb/ fichadetramitacao?idProposicao=18189>. Acesso em: 8 jun. 2016

BRASIL. Ministério da Saúde. Portaria nº 1.444, de 28 de dezembro de 2000. Estabelece incentivo financeiro para a reorganização da atenção básica à saúde bucal nos municípios por meio do Programa de Saúde da Família. Brasília, DF. 2000. Disponível em: <http:// www.camara.gov.br/sileg/integras/142359.pdf>. Acesso em: 8 jun. 2016.

BRASIL. Ministério da Saúde. Diretrizes da Política Nacional de Saúde Bucal. Brasília, DF, 2004.

Disponível em: <http://bvsms.saude.gov.br/bvs/publicacoes/politica_nacional_brasil_ sorridente.pdf $>$. Acesso em: 8 jun 2016 
BRASIL. Ministério da Saúde. Departamento de Atenção Básica. Histórico de Cobertura da Saúde da Família. Brasília, DF, 2016. Disponível em: <http://dab.saude.gov.br/portaldab/ historico_cobertura_sf.php> Acesso em: 19 nov. 2015.

BRASIL. Presidência da República. Casa Civil. Lei no 11.889, de 24 de dezembro de 2008. Regulamenta o exercício das profissões de Técnico em Saúde Bucal e Auxiliar em Saúde Bucal. Brasília, DF, 2008. Disponível em: <http://www.planalto.gov.br/ccivil_03/_Ato20072010/2008/Lei/L11889.htm>. Acesso em: 8 jun 2016.

BRASIL. Congresso Nacional. Câmara dos Deputados. Projeto de Lei no 1.140, de 28/05/2003, que regulamenta o exercício das profissões de Técnico em Higiene Dental e de Atendente de Consultório Dentário. Disponível em: <http://www.camara.gov.br/proposicoesWeb/ fichadetramitacao?idProposicao=117483>. Acesso em: 8 jun. 2016.

BRASIL. Congresso Nacional. Senado Federal. Projeto de Lei da Câmara nº 3, de 9/01/2007, que regulamenta o exercício das profissões de Técnico em Saude Bucal e Auxiliar em Saúde Bucal. Disponível em: http://www25.senado.leg.br/web/atividade/materias/-/materia/79741 Acesso em: 8 jun. 2016.

CAMPOS, G. W. S. O SUS entre a tradição dos Sistemas Nacionais e o modo liberalprivado para organizar o cuidado à saúde. Ciência \& Saúde Coletiva, Rio de Janeiro, v. 12, supl.

p. $1865-1874$, nov. 2007.

CARVALHO, C. L. Trabalho e profissionalização das categorias auxiliares em Odontologia. Revista Ação Coletiva. Brasília, DF, v. 2, n. 1, p. 25-33, 1999.

CHAVES, S. C. L. Oral health in Brazil: the challenges for dental health care models. Brazilian Oral Research, v. 26, n. supl 1, p.71-80, 2012.

CONSELHO FEDERAL DE EDUCAÇÃO (Brasil). Parecer no 460 de 06 de fev. de 1975. Dispõe sobre habilitação de Técnico em Higiene Dental e Atendente de Consultório Dentário. Brasília, DF, 1975. p. 20-24.

CONSELHO FEDERAL DE ODONTOLOGIA - CFO. (Brasil). Dados estatísticos. 2015. Disponível em: <http://www.cfo.org.br/servicos-e-consultas/dados-estatisticos/>. Acesso em: 29 nov. 2015.

DUNNING, J. M. Extending the field for dental auxiliary personnel in the United States. American Journal of Public Health, New York, v. 48, n. 8, p. 1059-1064, Aug. 1958.

FRAZÃO, P.; GONZÁLES, C. C.; ROSA, A. G. F. Ambiente de trabalho odontológico na perspectiva do Sistema Único de Saúde. Divulgação em Saúde para Debate, Londrina, n. 10, p. 21-28, jun. 1995 .

FRANCO, T. B.; MERHY, E. E. Programa Saúde da Família (PSF): contradições de um programa destinado à mudança do modelo tecnoassistencial. In: MERHY, E. E. et al. O trabalho em saúde: olhando e experienciando o SUS no cotidiano. São Paulo: Hucitec, 2007. Capítulo 3, p. 55-124. 
FRAZÃO, P.; CASTELLANOS, R. A. La participación del personal auxiliar de odontología en los sistemas locales de salud. Pan American Journal of Public Health, v. 5, n. 2, p. 106-115, feb. 1999.

FRAZÃO, P.; NARVAI, P. C. Lei n. 11.889/2008: avanço ou retrocesso nas competências do Técnico em Saúde Bucal? Trabalho, Educação e Saúde, Rio de Janeiro, v. 9, n. 1, p. 107-121, jun. 2011.

FRAZÃO, P.; NARVAI, P. C. Sistemas de trabalho em Odontologia: origens históricas e principais aplicações. In: PEREIRA, A. C. Tratado de Saúde Coletiva em Odontologia. São Paulo: Ed. Napoleão, 2009. p. 238-246.

FULTON, J. T. Experiment in dental care: results of New Zealand's use of school dental nurses. Geneva: World Health Organization, 1951.

GALLOWAY, J. et al. The Professionals Complementary to Dentistry: Systematic Review and Synthesis. York: Database of Abstracts of Reviews of Effects (DARE), 2004. Disponível em: <http://www.crd.york.ac.uk/CRDWeb/ShowRecord.asp?ID=12003008507> Acesso em: 19 nov. 2015.

HOPCRAFT, M. S. et al. Utilizing dental hygienists to undertake dental examination and referral in residential aged care facilities. Community Dentistry and Oral Epidemiology, Copenhagen, v. 39, n. 4, p. 378-384, Aug. 2011.

JOHNSON, Patricia M. Dental hygiene practice: international profile and future directions. International Dental Journal, London, v. 42, n. 6, p. 451-9, Dec. 1992.

JOHNSON, P. M. International profiles of dental hygiene 1987 to 2006: a 21-nation comparative study. International Dental Journal, London, v. 59, n. 2, p. 63-77, Apr. 2009.

Matus, C. Política, planejamento \& governo. 3. ed. São Paulo: IPEA, 1997. Tomo I.

NARVAI, P. C. et al Contra o técnico em higiene dental. Saúde em Debate, Londrina, v. 28, p. 59-65, mar. 1990.

NARVAI, P.C.; FRAZÃO, P. Saúde bucal no Brasil: muito além do céu da boca. Rio de Janeiro: Fiocruz, 2008. (Coleção Temas em Saúde).

NARVAI, P. C.; FRAZÃO, P. Técnico em higiene dental: hora de recuar? In: CONGRESSO DA FEDERAÇÃO INTERESTADUAL DOS ODONTOLOGISTAS, 5., 1999. Rio Quente. Anais... Rio quente: FSP/USP; FIO, 1999.

ORGANIZAÇÃO MUNDIAL DA SAÚDE. Trabalhando juntos pela saúde. Brasília: Ministério da Saúde, 2007. (Série B. Textos Básicos de Saúde).

SANGLARD-OLIVEIRA, C. A. et al. Atribuições dos Técnicos em Saúde Bucal na Estratégia Saúde da Família em Minas Gerais, Brasil. Ciência \& Saúde Coletiva, Rio de Janeiro, v. 18, n. 8, p. 2453-2460, 2013.

SAN MARTÍN-RODRÍGUEZ, L. et al. The determinants of successful collaboration: A review of theoretical and empirical studies. Journal of Interprofessional Care, v. 19, n. suppl. 1, p.132-147, May 2005. 
ZANETTI, C. H. G. Imputações ideológicas: derivações públicas e privadas do profissionalismo como crença na história da odontologia brasileira - um ensaio sobre o esvaziamento da ação. Brasília, DF: UnB/ObservaRH/Nesp, 2012. 